\title{
Gambaran Profil Lipid pada Pasien Infark Miokard Akut di RSUP M. Djamil Padang Periode 1 Januari 2011 - 31 Desember 2012
}

Lamuna Fathila ${ }^{1}$, Zulkarnain Edward $^{2}$, Rosfita Rasyid ${ }^{3}$

\begin{abstract}
Abstrak
Infark Miokard Akut (IMA) merupakan nekrosis otot jantung akibat terganggunya kebutuhan dan suplai oksigen ke jantung secara mendadak. Faktor risikonya adalah perubahan profil lipid yaitu Kolesterol total, Kolesterol LDL. Kolesterol HDL, dan trigliserida yang dikaitkan dengan pembentukan plak aterosklerosis. Manfaat penelitian ini untuk mengetahui gambaran profil lipid pada pasien IMA. Tujuan penelitian ini untuk mengetahui gambaran profil lipid pada pasien IMA di RSUP M. Djamil Padang periode 1 Januari 2011-31 Desember 2012. Penelitian dilakukan dengan metode deskriptif dengan desain cross sectional study di bagian Rekam Medik RSUP M. Djamil Padang. Hasil penelitian menunjukkan umur terbanyak pasien IMA 45-59 tahun, Jenis kelamin terbanyak pasien IMA adalah laki-laki, perbandingannya adalah $2,7: 1$, Pasien IMA yang memiliki kadar kolesterol total tinggi 79 orang $(38,92 \%)$ dan normal 124 orang $(61,08 \%)$, Pasien IMA yang memiliki kadar kolesterol LDL tinggi 76 orang $(37,44 \%)$ dan normal 127 orang (62,56\%), Pasien IMA yang memiliki kadar kolesterol HDL rendah 145 orang $(71,43 \%)$ dan normal 58 orang (28,57\%), dan Pasien IMA yang memiliki kadar trigliserida tinggi 44 orang (21,67\%) dan normal 159 orang $(78,33 \%)$.
\end{abstract}

Kata kunci: infark miokard akut, kolesterol total, kolesterol LDL, Kolesterol HDL, trigliserida

\section{Abstract}

Acute Myocardial Infarction (AMI) is a muscle necrosis of the heart through disruption of demand and supply of oxygen to the heart suddenly. Risk factors of AMI is a change of lipid profile (Total Cholesterol, LDL Cholesterol, HDL Cholesterol, and Triglycerides) associated with the formation of atherosclerotic plaque. The benefit of this research is to reveal the lipid profile in patients with AMI. The objective of this study was to determine the description of lipid profile in patients with AMI at RSUP M. Djamil Padang period January $1^{\text {st }}$, 2011-December $31^{\text {th }}$, 2012. The study was conducted with descriptive methods to the design of cross sectional study at the Medical Records Department of RSUP M. Djamil Padang. The results of this study indicate that the most age of the patients of AMI 45-59 years old, the most gender of AMI are male and the ratio 2.7 : 1, AMI patients with high total cholesterol levels 79 people (38.92\%) and normal 124 people (61.08\%), AMI patients with high LDL cholesterol levels 76 people (37,44\%) normal 127 people (62.56\%), AMI patients with low HDL cholesterol levels 145 people (71.43\%) and normal 58 people (28.57\%), and AMI Patients with high triglyceride levels 44 people (21.67\%) and normal 59 people (78.33\%).

Keywords: acute myocardial infarction, total cholesterol, LDL cholesterol, HDL cholesterol, triglyceride

Affiliasi penulis: 1. Pendidikan Dokter FK UNAND (Fakultas Kedokteran Universitas Andalas Padang), 2. Bagian Biokimia FK UNAND, 3. Bagian IImu Kesehatan Masyarakat FK UNAND.

Korespondensi: Lamuna Fathila, E-mail lamunafathila@rocketmail.com, Telp: 08116657778

\section{PENDAHULUAN}

Infark Miokard Akut (IMA) merupakan penyakit yang sangat sering ditemukan, tidak hanya di negara maju tetapi juga ditemukan di Negara berkembang. IMA merupakan salah satu manifestasi dari 
penyakit jantung iskemik atau dikenal juga dengan penyakit jantung koroner (PJK) yang mempunyai risiko morbiditas dan mortalitas. Menurut World Health Organization (WHO) dan World Health Federation, penyakit jantung akan menjadi salah satu penyebab utama mortalitas di negara-negara Asia pada tahun $2010 .^{1}$

IMA adalah nekrosis otot jantung akibat terganggunya homeostasis, yaitu kebutuhan dan suplai oksigen ke jantung secara mendadak. Hal ini disebabkan oleh rupturnya plak ateroma yang menginduksi agregasi trombosit, pembentukan trombus, dan spasme koroner sehingga menyumbat arteri koroner. $^{2}$

Di Amerika Serikat, sekitar 650 ribu diantaranya mengalami IMA baru dan 450 ribu berulang setiap tahun. ${ }^{3}$ Infark miokard merupakan manifestasi utama dari penyakit jantung iskemik pada $43 \%$ laki-laki dan $29 \%$ perempuan. ${ }^{4}$ Sebuah penelitian di Pusat Jantung Nasional Harapan Kita (PJNHK) Jakarta pada tahun 2009, didapatkan 196 pasien adalah IMA. ${ }^{5}$

Profil kesehatan Indonesia 2008 menyatakan bahwa PJK merupakan kasus penyakit yang terbanyak pada pasien penyakit jantung di rumah sakit Indonesia tahun 2007 baik dari data pasien yang dirawat jalan maupun pasien yang dirawat inap dengan Case Fatality Rate (CFR) tertinggi terjadi pada IMA $(13,49 \%)$, gagal jantung $(13,42 \%)$, dan penyakit jantung lainnya $(13,49 \%){ }^{6}$ Survei Kesehatan Rumah Tangga (SKRT) Departemen Kesehatan Republik Indonesia menyatakan bahwa peringkat dari penyakit kardiovaskular sebagai penyebab kematian semakin meningkat. Pada tahun 1972, penyakit kardiovaskular berada pada urutan ke-11 sebagai penyebab kematian, dan pada tahun 1986 berubah menjadi urutan ke-3. Persentase kematian akibat penyakit kardiovaskular di tahun 1998 adalah 24,4\% dan diperkirakan $30 \%$ dari semua penyebab kematian di seluruh dunia adalah penyakit jantung koroner, khususnya IMA. ${ }^{7}$ Pada tahun 2000 terdapat 1600 orang meninggal dari 4.253.510 penduduk Sumatera Barat akibat penyakit jantung dan pembuluh darah setiap tahun. Sebanyak 400 orang di antaranya meninggal sebelum mendapat perawatan medis. ${ }^{8}$

Faktor risiko timbulnya IMA adalah perubahan dari profil lipid yaitu Kolesterol total, Kolesterol LDL
(LDL-C/Low Density Lipoprotein Cholesterol), Kolesterol HDL (HDL-C/High Density Lipoprotein Cholesterol, dan trigliserida yang dikaitkan dengan pembentukan plak aterosklerosis. ${ }^{9}$ Jika kolesterol total, kolesterol LDL dan trigliserida darah melewati batas normal, maka akan diendapkan pada dinding pembuluh darah dan membentuk bekuan yang dapat menyumbat pembulun darah. Jika kolesterol HDL mengalami penurunan, maka fungsi HDL sebagai penyapu kolesterol akan menurun dan menyebabkan kadar LDL darah mengikat yang juga dikaitkan sebagai pembentukan plak aterosklerosis. ${ }^{10}$

Kadar ideal kolesterol total pada orang dewasa adalah <200 mg/dl, kolesterol LDL $<160 \mathrm{mg} / \mathrm{dl}$, kolesterol HDL (laki-laki $>35 \mathrm{mg} / \mathrm{dl}$ dan perempuan $>45 \mathrm{mg} / \mathrm{dl}$ ), dan trigliserida 60-160 mg/dl. ${ }^{11} \mathrm{Di}$ beberapa daerah memiliki nilai kolesterol yang hamper sama yaitu Surabaya tahun 1985:195 mg/dl, Ujung Pandang tahun 1990: $219 \mathrm{mg} / \mathrm{dl}$ dan Malang 1994: $206 \mathrm{mg} / \mathrm{dl}^{12}$

Heart study menunjukkan pembentukan plak aterosklerosis merupakan akibat dari gangguan metabolism lipoprotein yang meliputi peningkatan kadar LDL kolesterol dan penurunan kadar HDL kolesterol. Peningkatan kadar kolesterol total, trigliserida, kolesterol LDL dan penurunan kolesterol HDL merupakan faktor penentu dalam perkembangan aterosklerosis dan IMA. ${ }^{13}$

\section{METODE}

Ini adalah penelitian deskriptif dengan desain cross sectional study untuk mengetahui gambaran profil lipid pada pasien infark miokard akut di RSUP M. Djamil Padang periode 1 Januari 2011 - 31 Desember 2012. Populasi penelitian adalah semua data pasien IMA dengan kadar kolesterol total, kolesterol LDL, kolesterol HDL dan trigliserida di RSUP M. Djamil Padang periode 1 Januari 2011 - 31 Desember 2012. Sampel yang digunakan adalah bagian dari populasi yang memenuhi kriteria inklusi dan kriteria ekslusi yaitu sebanyak 203 sampel. Data yang diperoleh dicatat secara manual berdasarkan variabel yang dibutuhkan dari penelitian, kemudian data tersebut ditabulasikan dan ditampilkan dalam bentuk tabel distribusi frekuensi dan gambar. 
HASIL

Tabel 1. Distribusi frekuensi subjek penelitian menurut umur

\begin{tabular}{ccc}
\hline Umur (tahun) & Frekuensi & $\%$ \\
\hline$<40$ & 6 & 2,96 \\
$40-59$ & 105 & 51,72 \\
$60-79$ & 81 & 39,9 \\
$>79$ & 11 & 5,42 \\
\hline Jumlah & 203 & 100 \\
\hline
\end{tabular}

Tabel 1 menunjukkan bahwa frekuensi terbanyak pasien yang menderita IMA yang dijadikan subjek penelitian berada pada kelompok umur 40-59 tahun sebanyak 105 orang $(51,72 \%$ dari keseluruhan pasien IMA) dan yang terendah berada pada kelompok umur $<40$ tahun sebanyak 6 orang $(2,96 \%$ dari keseluruhan pasien IMA).

Tabel 2. Distribusi frekuensi subjek penelitian menurut jenis kelamin

\begin{tabular}{ccc}
\hline Jenis kelamin & Frekuensi & $\%$ \\
\hline Laki-laki & 148 & 72,91 \\
Perempuan & 55 & 27,09 \\
\hline Jumlah & 203 & 100 \\
\hline
\end{tabular}

Berdasarkan Tabel 2 dapat dilihat bahwa frekuensi terbanyak pasien yang menderita IMA yang dijadikan subjek penelitian berjenis kelamin laki-laki sebanyak 148 orang $(72,91 \%$ dari keseluruhan pasien IMA). Sedangkan pasien IMA yang berjenis kelamin perempuan sebanyak 55 orang $(27,09 \%$ dari keseluruhan pasien IMA).

Tabel 3. Distribusi frekuensi subjek penelitian menurut kadar kolesterol total

\begin{tabular}{ccc}
\hline $\begin{array}{c}\text { Kolesterol total } \\
(\mathbf{m g} / \mathbf{d l})\end{array}$ & Frekuensi & $\%$ \\
\hline$<200$ & 124 & 61,08 \\
$200-239$ & 48 & 23,65 \\
$>240$ & 31 & 15,27 \\
\hline Jumlah & 203 & 100
\end{tabular}

Data pada Tabel 3 menunjukkan bahwa frekuensi terbanyak pasien yang menderita IMA yang dijadikan subjek penelitian yang memiliki kadar kolesterol total $<200 \mathrm{mg} / \mathrm{dl}$ sebanyak 124 orang (61,08\% dari keseluruhan pasien IMA), 200-239 mg/dl sebanyak 48 orang $(23,65 \%$ dari keseluruhan pasien IMA), dan $>240 \mathrm{mg} / \mathrm{dl} \quad(15,27 \%$ dari keseluruhan pasien IMA).

Tabel 4. Distribusi frekuensi subjek penelitian menurut kadar kolesterol LDL

\begin{tabular}{ccc}
\hline $\begin{array}{c}\text { Kolesterol LDL } \\
(\mathbf{m g} / \mathbf{d l})\end{array}$ & Frekuensi & $\%$ \\
\hline$<\mathbf{1 3 0}$ & 127 & 62,56 \\
$\mathbf{1 3 0 - 1 5 9}$ & 38 & 18,72 \\
$>\mathbf{1 6 0}$ & 38 & 18,72 \\
\hline Jumlah & 203 & 100 \\
\hline
\end{tabular}

Tabel 4 menunjukkan bahwa frekuensi terbanyak pasien yang menderita IMA yang dijadikan subjek penelitian yang memiliki kadar kolesterol LDL $<130 \mathrm{mg} / \mathrm{dl}$ sebanyak 127 orang $(62,56 \%$ dari keseluruhan pasien IMA), 130-159 mg/dl sebanyak 38 orang $(18,72 \%$ dari keseluruhan pasien IMA) dan $>160$ $\mathrm{mg} / \mathrm{dl}$ sebanyak 38 orang $(18,72 \%$ dari keseluruhan pasien IMA).

Tabel 5. Distribusi frekuensi subjek penelitian menurut kadar kolesterol HDL

\begin{tabular}{ccc}
\hline $\begin{array}{c}\text { Kolesterol HDL } \\
(\mathbf{m g} / \mathbf{d l})\end{array}$ & Frekuensi & $\%$ \\
\hline$>45$ & 58 & 28,57 \\
$35-45$ & 73 & 35,96 \\
$<35$ & 72 & 35,47 \\
\hline Jumlah & 203 & 100 \\
\hline
\end{tabular}

Data pada Tabel 5 menunjukkan bahwa frekuensi terbanyak pasien yang menderita IMA yang dijadikan subjek penelitian yang memiliki kadar kolesterol HDL >45 mg/dl sebanyak 58 orang $(28,57 \%$ dari keseluruhan pasien IMA), 35-45 mg/dl sebanyak 73 orang $(35,96 \%$ dari keseluruhan pasien IMA), dan $<35 \mathrm{mg} / \mathrm{dl}$ sebanyak 72 orang $(35,47 \%$ dari keseluruhan pasien IMA). 
Tabel 6. Distribusi frekuensi subjek penelitian menurut kadar trigliserida

\begin{tabular}{ccc}
\hline $\begin{array}{c}\text { Trigliserida } \\
(\mathbf{m g} / \mathbf{d l})\end{array}$ & Frekuensi & $\%$ \\
\hline$<150$ & 159 & 78,32 \\
$150-250$ & 31 & 15,27 \\
$250-500$ & 10 & 4,93 \\
$>500$ & 3 & 1,48 \\
\hline Jumlah & 203 & 100 \\
\hline
\end{tabular}

Data pada Tabel 6 menunjukkan bahwa frekuensi terbanyak pasien yang menderita IMA yang dijadikan subjek penelitian yang memiliki kadar trigliserida $<150 \mathrm{mg} / \mathrm{dl}$ sebanyak 159 orang (78,32\% dari keseluruhan pasien IMA), 150-250 mg/dl sebanyak 31 orang $(15,27 \%$ dari keseluruhan pasien IMA), $250-500 \mathrm{mg} / \mathrm{dl}$ sebanyak 10 orang (4,93\% dari keseluruhan pasien IMA), dan $>500 \mathrm{mg} / \mathrm{dl}$ sebanyak 3 orang $(1,48 \%$ dari keseluruhan pasien IMA).

\section{PEMBAHASAN}

Umur terbanyak pasien IMA di RSUP M. Djamil Padang perode 1 Januari - 31 Desember 2012 adalah 45-59 tahun (51,72\%). Menurut literatur, insiden IMA menigkat 40-60 tahun sebanyak lima kali lipat di karenakan pada umur $>40$ tahun terjadi penurunan fungsi dari organ-organ didalam tubuh termasuk jantung sehingga arteri koroner mengalami vasokonstriksi kemudian terjadi gangguan aliran darah ke miokard yang akan menyebabkan nekrosis otot jantung, hal ini sesuai dengan hasil penelitian Sargowo pada tahun 2001 mengenai penurunan kadar triglisireda dan lipoprotein sebagai faktor risiko penyakit jantung koroner, bahwa penderita IMA meningkat secara nyata pada kelompok umur 39-76 tahun. $^{13}$

Jenis kelamin terbanyak pasien IMA di RSUP M. Djamil Padang periode 1 Januari 2011 - 31 Desember 2012 adalah laki-laki (72,91\%), hal ini sesuai dengan hasil penelitian Sulviana pada tahun 2008 bahwa jenis kelamin terbanyak pada penyakit IMA adalah laki-laki $(61,3 \%) .{ }^{14}$

Hasil penelitian ini didapatkan 79 orang $(38,92 \%)$ yang memiliki kadar kolesterol total > 200 $\mathrm{mg} / \mathrm{dl}$, hal ini hampir sama dengan penelitian Sargowo pada tahun 2001 didapatkan peningkatan dari kadar kolesterol total sebesar $42,5 \%$. $^{13}$ Menurut literatur, kadar kolesterol total sebaiknya adalah 200 mg/dl, apabila > $200 \mathrm{mg} / \mathrm{dl}$ kolesterol tersebut akan disimpan dan menempel didalam pembuluh darah, sehingga nantinya akan menimbulkan pengendapan kolesterol didalam pembuluh darah, hal tersebut menyebabkan risiko untuk terjadinya PJK semakin meningkat. ${ }^{10,12}$ Banyaknya kadar kolesterol yang rendah pada sampel $(61,08 \%)$ diduga disebabkan oleh sampel yang mulai mengurangi konsumsi bahan pangan yang tinggi kandungan kolesterolnya. Secara umum dapat dikatakan bahwa pada setiap satu persen peningkatan kadar kolesterol darah terjadi dua persen peningkatan risiko terkena penyakit jantung koroner. ${ }^{15}$

Hasil penelitian ini juga didapatkan 76 orang $(37,44 \%)$ yang memiliki kadar kolesterol LDL >130 mg/dl diantaranya 38 orang (18,72\%) memiliki kadar kolesterol LDL 130-159 mg/dl dan 38 orang (18,72\%) memiliki kadar kolesterol LDL >160 mg/dl, hal ini sesuai dengan penelitian dimana didapatkan peningkatan kadar kolesterol LDL sebesar $13,2 \%{ }^{13}$ Kolesterol LDL berukuran kecil sehingga mudah masuk ke dinding pembuluh darah, terutama jika dinding tersebut rusak karena beberapa faktor risiko seperti umur, jenis kelamin, merokok, hipertensi atau faktor keturunan. ${ }^{16}$

Banyaknya kadar kolesterol LDL yang rendah $(62,56 \%)$ mungkin dikarenakan faktor risiko lain yang diduga berpengaruh seperti tidak merokok, tidak terdapat riwayat hipertensi atau tidak terdapat faktor keturunan.

Kolesterol HDL merupakan jenis kolesterol yang mengangkut kolesterol dari pembuluh darah kembali ke hati untuk dibuang. Apabila terjadi penurunan kadar kolesterol HDL, akan mengurangi peran HDL sebagai penangkap kolesterol pada pengangkutan-balik kolesterol dari jaringan ke hati, sehingga kolesterol yang menumpuk disepanjang dinding pembuluh darah tidak diangkut kembali ke hati. Hal tersebut nantinya akan menyebabkan pembentukan plak karena penumpukan kolesterol di sepanjang dinding pembuluh darah (aterosklerosis). ${ }^{12}$

Penelitian ini mendapatkan 73 orang (35,96\%) memiliki kadar kolesterol HDL 35-45 mg/dl dan 72 orang $(35,47 \%)$ memiliki kadar kolesterol HDL <35 $\mathrm{mg} / \mathrm{dl}$, hal ini sesuai dengan penelitian Sargowo 
(2001) didapatkan kadar rerata kolesterol HDL pada infark sebesar 27,92-30,17 mg/dl (<45 mg/dl). ${ }^{13}$

Berolahraga keras dapat meningkatkan kolesterol HDL di dalam darah sampai 20-30 persen, sehingga terdapat kemungkinan bahwa kemampuan kolesterol HDL menyingkirkan kolesterol biasa meningkat selama latihan fisik, namun hal tersebut tidak bertahan lama karena apabila berhenti berolahraga, kadar kolesterol HDL dan kolesterol biasa kembali ke kadar semula sebelum olahraga dimulai. Oleh karena itu, jika ingin memperbaiki dan mengontrol kadar kolesterol dalam darah maka perlu melakukan olahraga secara teratur. ${ }^{15}$ Menurut beberapa hasil penelitian dalam Durstine pada tahun 2001, kebiasaan berolahraga dapat menurunkan kadar trigliserida dan kadar LDL namun tidak selalu turun. Kadar kolesterol cenderung tidak berubah selama berolahraga. Namun, kadar HDL meningkat jika seseorang melakukan olahraga aerobik yang dilakukan setidaknya 12 minggu berturut-turut walaupun tidak selalu berhasil. ${ }^{17}$

Sebanyak $17,8 \%$ pasien IMA memiliki peningkatan kadar trigliserida $(>150 \mathrm{mg} / \mathrm{dl}) .{ }^{13}$ Dari penelitian ini didapatkan 31 orang $(15,27 \%)$ memiliki kadar trigliserida $150-250 \mathrm{mg} / \mathrm{dl}$, 10 orang (4,93\%) memiliki kadar trigliserida 250-500 mg/dl, dan 3 orang $(1,48 \%)$ memiliki kadar trigliserida $>500 \mathrm{mg} / \mathrm{dl}$ atau secara keseluruhan didapatkan sebanyak 44 orang $(21,67 \%)$ memiliki peningkatan kadar trigliserida (>150 $\mathrm{mg} / \mathrm{dl})$. Menurut literatur, trigliserida yang lebih dikenal triasilgliserol terdiri dari 3 jenis lemak yaitu lemak jenuh, lemak tidak tunggal dan lemak jenuh ganda. Kadar trigliserida yang tinggi merupakan faktor resiko untuk terjadinya PJK terutama IMA dilihat dari peran trigliserida dalam pengangkutan serta penyimpanan lipid. ${ }^{12}$ Rendahnya kadar trigliserida subjek (78,32\%) diduga disebabkan oleh status gizi contoh yang umumnya normal, tidak mengkonsumsi alkohol, dan sudah mulai mengurangi makanan yang tinggi gula dan lemak.

\section{KESIMPULAN}

Hasil penelitian terhadap 203 kasus IMA di RSUP M. Djamil Padang periode 1 Januari 2011 - 31 Desember 2012 didapatkan umur terbanyak pada pasien IMA adalah 45-59 tahun dan jenis kelamin pasien terbanyak pada pasien IMA laki-laki, dimana perbandingan antara laki-laki dan perempuan adalah $2,7: 1$.

Data profil lipid yang dikumpulkan di Bagian Rekam Medik RSUP M. Djamil Padang didapatkan pasien IMA yang memiliki kadar kolesterol total tinggi adalah sebanyak 79 orang (38,92\%) dan normal adalah sebanyak 124 orang (61,08\%), Pasien IMA yang memiliki kadar kolesterol LDL tinggi adalah sebanyak 76 orang $(37,44 \%)$ dan normal adalah sebanyak 127 orang (62,56\%), Pasien IMA yang memiliki kadar kolesterol HDL rendah adalah sebanyak 145 orang $(71,43 \%)$ dan normal adalah sebanyak 58 orang $(28,57 \%)$, dan Pasien IMA yang memiliki kadar trigliserida tinggi adalah sebanyak 44 orang $(21,67 \%)$ dan normal adalah sebanyak 159 orang $(78,33 \%)$

\section{UCAPAN TERIMA KASIH}

Ucapan terima kasih kepada dr. Zulkarnain Edward. MS, PhD dan Dr. dr. Rosfita Rasyid, M.Kes atas bimbingan, nasehat dan bantuannya dalam penelitian ini.

\section{DAFTAR PUSTAKA}

1. Septiani S. Kapita selekta epidemiologi penyakit tidak menular. 2010. [Diunduh 28 februari 2013]. Tersedia dari: URL: HYPERLINK http://www. scribd.com/riska ferdian/d/70978762/2-IIepidemiologi-penyakit-jantung-koroner

2. Setianto BY, Rochmah W, Nurohman A. Hubungan angka leukosit pada infark miokard akut dengan kejadian cardiac event selama dirawat di rumah sakit. Berkala IImu Kedokteran. Yogyakarta. 2003;35(1):32.

3. Antman EM, Anbe DT, Armstrong PW, Bates ER, Hand M, Hochman JS, et al. Management of patients with ST elevation myocardial infarction. ACC / AHA for guidelines. 2004.

4. Komaroff AL, Woo B. Kesehatan perempuan. Dalam: Isselbacher KJ, Braunwald E, Wilson JD, Martin JB, Fauci AS, Kasper DL, editor (penyunting). Prinsip-Prinsip IImu Penyakit Dalam Harisson. Edisi ke-13. Yogyakarta: EGC; 1995.

5. Danny SS, Roebiono PS, Susanto AM, Kasim M. Factor influencing major cardiovascular event post 
acute myocardial infarction in woman. Jurnal kardiologi Indonesia. 2009;13(1):3-12.

6. Departemen Kesehatan Republik Indonesia. Profil kesehatan Indonesia 2008. 2009; 62.

7. Sulastomo H. Sindroma koroner akut dengan gangguan metabolik pada wanita usia muda pengguna kontrasepsi hormonal. 2010. [diunduh 5 Maret 2013]. Tersedia dari: URL: HYPERLINK http://www.kardiologi-ui.com/newsread.php?id=355

8. Mutia R. Pengaruh yoga terhadap peningkatan kadar kolesterol HDL dan penurunan LDL dalam darah pada pasien jantung koroner. 2012 [diunduh 10 Maret 2013]. Tersedia dari : URL : HYPERLINK http://repository.unand.ac.id

9. Botham KM, Mayes PA, Editor Wulandari N, et al. Sintesis, pengangkutan, dan ekskresi kolesterol. Dalam :Murray RK, Granner DK, Rodwell VW, editor (penyunting). Biokimia Harper (terjemahan). Edisi ke-27. Jakarta: ECG; 2009.

10. Harlinawati Y. Terapi jus untuk kolesterol. Jakarta: Puspa Swara; 2008.

11. Marks DB, Marks AD, Smith CM. Biokimia Kedokteran Dasar (terjemahan). Jakarta: EGC; 2000.
12. Anwar TB. Dislipidemia sebagai resiko penyakit jantung korner. 2004 [diunduh 6 Maret 2013]. Tersedia dari: URL: HYPERLINK http://library.usu. ac.id/download/fk/gizi-bahri3.pdf

13. Sargowo. Peranan kadar trigliserida dan lipoprotein sebagai faktor risiko penyakit jantung koroner (studi pendahuluan). 2001 [diunduh 8 Maret 2013]. Tersedia dari: URL: HYPERLINK http://www. tempo.co.id/medika/arsip/072002/art-1.htm

14. Sulviana N. Analisis hubungan gaya hidup dan pola makan dengan kadar lipid darah dan tekanan darah pada penderita jantung koroner. 2008 [diunduh 14 Maret 2013]. Tersedia dari: URL: HYPERLINK http://repository.ipb.ac.id/bitstream/ handle/123456789/2615/A08nsu.pdf?sequence $=5$

15. Heslet L. Kolesterol yang perlu anda ketahui. Anton Adiwiyoto (Penerjemah). Cholesterol. Jakarta: Kesaint Blanc; 2007.

16. Fikri F. Bahaya kolesterol. Yogyakarta: Ar-Ruzz Media; 2009.

17. Durstine JL. Exercise and Lipid disorders. Dalam: Thompson PD, editor (penyunting). Exercise and Sports Cardiology. New York: McGraw Hill; 2001. 